\title{
UNA SALUD POSITIVA NO ES SUEÑO IMPOSIBLE
}

\author{
Bárbara Ann Giles*
}

La Organización Mundial de la Salud define al individuo sano como aquel que goza de completo bienestar físico, mental y social y no simplemente la ausencia de enfermedad o invalidez.

Uno dolos derechos fundamentales de todos los seres humanos sin distinciones de raza, religión, ideas políticas, condiciones económicas o sociales es el goce pleno de la salud. La persona sana es la principal riqueza de la sociedad y por tal razón, es importante aprender a conservar la salud desde el momento de concepción.

Lo que la gente hace es más importante para su salud que lo que la gente conoce acerca de ella. Hoy en día la mayor preocupación de los educadores para la salud es la de cómo lograr que la gente, los grupos y comunidades adopten realmente comportamientos facilitadores de salud.

La Educación para la Salud debe contemplarse en una estrategia amplia de promoción de la salud en donde la comunidad asuma un protagonismo efectivo, y sus objetivos vayan más allá de los establecimientos educativos.

\section{¿Qué es un comportamiento saludable?}

\section{La actividad física regular:}

La vida del hombre ha sido cortada por los avances tecnológicos, porque ha fomentado el descuido del estado físico, puesto que esos adelantos tienden a eliminar la fatiga física de las labores cotidianas. La falta de movilidad y la aplicación cada vez menor de la energía del cuerpo para efectuar un trabajo ha puesto, según los científicos, al ser humano en las puertas de la muerte 10 a 20 años antes que nuestros abuelos.

\section{Beneficios de la actividad física bien dirigida:}

1. Ayudar a demorar, si no impedir el comienzo o reducir la severidad de varias de las principales enfermedades degenerativas responsables por parte de las incapacidades prematuras.

2. Mejorar las funciones circulatorias y respiratoria.

3. Aumentar la flexibilidad y movilidad de las articulaciones, fortalecer los tendones y la fijación muscular.

4. Ayudar a combatir la obesidad, al gastar calorías y a activar las funciones vitales.

5. Rebajar el nivel de grasas en la sangre, disminuir el riesgo de arteriosclerosis.

6. Aliviar la tensión psíquica y permitir descargar la agresividad con lo que favorece la relajación, el reposo y el sueño.

7. Mejorar la actividad corporal, el aspecto físico y la imagen que uno tiene de sí mismo.

8. Contribuir a una vejez vigorosa y saludable.

\footnotetext{
* Profesora del Dpto de E.F. U.PN.
} 


\section{Riesgos de la actividad física no dirigida:}

1. En personas asmáticas puede originar un ataque durante el ejercicio excesivo.

2. En diabéticos es frecuente las bajas en los niveles de azúcar, y que originan graves accidentes por la pérdida del conocimiento.

3. El ejercicio mal practicado en extremo por las mujeres puede ocasionar el cese de la menstruación a causa de la reducción de estrógeno y que aumenta el riesgo de la osteoporosis.

4. En personas con afecciones respiratorias leves como ocurren con los fumadores "moderados" poseen pulmones que no resisten una mayor ventilación y que originan múltiples problemas orgánicos y de índole cardiorrespiratorio.

5. Por desconocimiento de los límites biológicos se incurren en excesos que originan sobrecarga cardiaca y pueden ocasionar la muerte.

6. Si se practica una actividad física en la cual el organismo conserva niveles o residuos de alcohol, puede originar un sin número de enfermedades que en ocasiones son fatales: infarto del miocardio; derrame cerebral, pérdida del conocimiento.

\section{Prácticas adecuadas de higiene}

La higiene es una rama fundamental de la medicina y una de las funciones básicas de la higiene diaria es tonificar el organismo y suministrar una sensación de bienestar.

La conservación completa, sana y estable del cuerpo humano debe estar basada en reglas de higiene que por lo general la mayoría de nosotros incumplimos y desconocemos.

La mayoría de las enfermedades que se propagan en nuestro medio se deben principalmente al descuido de nosotros mismos en cuestiones de conceptos generales de higiene.

La piel protege y conserva la temperatura corporal, impide la penetración de elementos extraños. Se encuentran en la piel terminaciones nerviosas, vasos sanguíneos y folículos pilosos; glándulas sudoríparas que conservan la humedad y glándulas sebáceas cuyas secreciones grasas la preservan y flexibilizan.

Debido a su humedad y su cálida temperatura, la piel, aloja una enorme cantidad de microorganismos que lejos de ser peligrosos, conservan el equilibrio natural de la epidermis. Una higiene racional ha de ir encaminada a evitar que la suciedad externa o una acumulación indebida de secreciones alteren ese equilibrio.

\section{Normas generales para una correcta higiene cotidiana}

La ducha diaria no es solamente como medida higiénica, sino también como manera de activar la circulación sanguínea y tonificar la piel y los músculos, sin olvidar sus beneficios, efectos sobre el sistema nervioso.

Los ojos del hombre moderno están sometidos a un sobre esfuerzo frecuente y por otra parte, al polvo, humo y otros agentes contaminantes. 
El lavado matinal de cara o el agua que se cuele en los ojos durante la ducha no constituye una medida higiénica suficiente y la gente que nota con frecuencia los ojos enrojecidos y cansados debería convertir el baño ocular en una costumbre diaria.

\section{La higiene de la boca y los dientes:}

Las 2 enfermedades más comunes en el hombre occidental son las caries dentales y la gingivitis; ambas relacionadas con nuestros hábitos alimenticios. Es necesario cepillarse los dientes al menos una vez al día (preferencialmente después de cenar); aunque lo ideal es hacerlo después de cada comida.

Para completar la higiene bucal conviene cepillar también suavemente la superficie de la lengua, donde se acumule bacterias y restos de comida.

La visita anual o semestral al dentista para una revisión y limpieza a fondo de dientes y encías es el complemento indispensable de una correcta higiene bucal.

\section{La higiene de las manos:}

La higiene de las manos es especialmente importante, porque son una de las partes del cuerpo más expuestas y más propensas a contaminarse por contacto de gérmenes o de sustancias tóxicas.

\section{La higiene de los Pies:}

La mayoría de los problemas de los pies son causados por el uso de calzados inadecuados. El calzado suele ser responsable de problemas relacionados directamente con la higiene. Las personas a las que sudan mucho los pies deben evitar los zapatos con suelo de plástico o goma, que implica la transpiración. Conviene usar calcetines de algodón o lana, ya que las fibras sintéticas también la dificultan.

\section{La higiene urbana:}

Las medidas sanitarias que deben cumplirse para la reunión de habitantes en un espacio reducido no sea obstáculo para la salud y el bienestar de cada uno de los individuos.

La salud y el bienestar de los habitantes de una ciudad dependen en parte de los servicios de limpieza que asegura la eliminación de basuras, limpieza de las calles y provisión de agua potable.

\section{Prácticas nutricionales adecuadas}

La nutrición es el alimento ingerido y la forma en que el cuerpo lo aprovecha. Una nutrición adecuada es esencial para una buena salud a través de toda la vida comenzando desde la vida prenatal y extendiéndose hasta la muerte.

Para hacer frente a los problemas de la vida moderna, es incuestionablemente necesario contar con una buena salud física y mental, y la base de ésta es una buena alimentación.

Lo fundamental es una alimentación sana y equilibrada, es obtener a través de la planificación de la dieta diaria las cantidades adecuadas de todos y cada uno de los grupos de nutrientes básicos. 
La clase y la calidad de los alimentos tienen un efecto definitivo sobre el crecimiento, la habilidad para aprender, la capacidad para el desarrollo físico, la resistencia a las infecciones, la longevidad, la salud vigorosa y el grado de bienestar.

La nutrición de la gente en Colombia es deficiente no tanto porque el país carezca de suficientes alimentos para proporcionar a su población una dieta apropiada, sino porque los hábitos nutritivos de la familia colombiana son defectuosos, a causa de la ignorancia del valor nutricional de los diversos productos. También los factores sociales económicos y culturales afectan la condición nutricional de un individuo, una familia, una comunidad y una nación. Un programa nutricional debe mejorar los hábitos nutricionales de los niños y de los adultos e influir en la escogencia inteligente de los alimentos, con arreglo a los recursos disponibles.

La educación nutricional es parte fundamental de la educación para la salud y como tal, es un proceso de aprendizaje que nace de las necesidades de la salud, alimentada con el conocimiento de la salud y que produce una acción individual y comunal, inteligente, constructiva y saludable.

\section{La habilidad a relajarse:}

El estrés es uno de los mayores enemigos de la salud, es una respuesta biopsicosocial del individuo frente a los estímulos externos e internos; una acumulación excesiva de la tensión lógica y natural que precede a cualquier decisión que uno se disponga a emprender.

\section{El estrés se compone de 3 elementos:}

El estímulo o agente que puede ser interior o exterior.

El proceso de interpretación de ese estímulo y su ubicación en un contexto.

La tensión o reacción, los cambios físicos de los movimientos, variaciones emocionales y de pensamiento.

\section{¿Quién está sujeto al estrés?}

Todas las personas en menor o mayor grado sufren de esta enfermedad. Las personas impacientes, competitivas, ambiciosas, que viven bajo la presión del tiempo, del honor o en términos de ser importantes sufren más que otras personas. La persona que sufre de estrés siente su cuerpo tenso, y sus movimientos se hacen espásticos. Se afectan los músculos lisos, el corazón y el intestino. Aparecen úlceras y hasta infartos cardíacos. La persona estresada sufre alteraciones a nivel del sistema nervioso, dolores de cabeza; falta de capacidad de concentración, irritabilidad, depresión, etc.

\section{¿Como detectar el estrés?}

Dificultad en tomar decisiones que antes eran fáciles. Dificultad para concentrarse. Fumar o beber más de lo habitual. Pérdida del apetito. Cansancio fuera de lo común.

\section{Cómo reducir el estrés y relajarse.}

Planear el trabajo, para que no sea necesario trabajar más de 10horas diarias.

Reservar por lo menos 1 día de cada semana para descansar de la rutina del trabajo. 
Hacer ejercicios físicos regularmente, preferentemente al aire libre.

Examinar los propios hábitos de alimentación y equilibrar la dieta, eliminando el exceso de azúcar y aumentando el consumo de vegetales frescos y crudos.

Dormir suficiente.

Tomar unas vacaciones; cultivar otro interés no relacionado con el trabajo.

Expresar abiertamente los sentimientos.

Hacer esfuerzos por cambiar las cosas que le generan ansiedad.

Una salud positiva depende en gran parte del interés y de la acción inteligente de la comunidad, individual y colectivamente. Sin embargo, despertar ese interés y esa acción contribuye en forma decisiva el educador.

\section{BIBLIOGRAFIA}

KATCH, Frank L., Sport, Health and Nutrition, 1984 Olympic Scientific Congress, Vol.2 Human Kinetics Publishers, Inc. Champaign, Illinois, 1986.

LOWENDBERG, Wilson; TODHUNTER; FEENEY y SAVAGE, Alimentos y El Hombre, Limusa-Wiley, Mexico, Título del original Inglés: Food and Man.

TEFFEL, Marc, El Naturismo Fuente de Salud, Editorial Ramos Majos, Barcelona, España 1981. 